\title{
Alfabetização no Espírito Santo: o método mútuo ou monitorial ${ }^{1}$
}

\section{Reading and writing teaching in Espírito Santo: the mutual instruction or monitorial system}

\author{
Cláudia Maria Mendes Gontijo²
}

\begin{abstract}
RESUMO
Este texto tem por finalidade analisar o Regimento Interno das Aulas Publicas de 1. ${ }^{\text {as }}$ Letras da Província do Espírito Santo e o método de ensino da leitura e da escrita concretizado nesse Regimento. Para desenvolvimento do estudo, utilizamos a pesquisa documental. $\mathrm{O}$ artigo conclui que o uso do método mútuo possibilitou a permanência de modelos tradicionais de ensino da leitura e da escrita baseados no estudo sistemático das letras, das sílabas, da frase e, finalmente, da leitura de textos religiosos e de outros, que visavam à constituição nos indivíduos de sentimentos religiosos e patrióticos. Conclui ainda que a adoção desse método, tendo em vista as condições de funcionamento das escolas, representou a falta de interesse de o Estado agroexportador e escravocrata oferecer condições mínimas de funcionamento das escolas, principalmente quanto à garantia de formação e remuneração adequada dos professores.
\end{abstract}

Palavras-chave: história da alfabetização; ensino da leitura; ensino da escrita; método mútuo.

1 A pesquisa foi financiada pela Faculdade de Ciências Sociais e Tecnológicas do Espírito Santo (FACITEC/ES), Brasil.

2 Doutora em Educação pela Faculdade de Educação da Universidade Estadual de Campinas (FE/ UNICAMP). Pós-Doutorado na UC Berkeley, CA. Integrante da Linha de pesquisa Educação e Linguagens do Programa de Pós-Graduação em Educação da Universidade Federal do Espírito Santo (UFES), Brasil. 


\begin{abstract}
This text aims at analyzing the Regimento Interno das Aulas Publicas de 1. ${ }^{\text {as }}$ Letras of the Espírito Santo Province (1871) and the mutual instruction implemented in this Regulation, emphasizing the guidelines to the practice of reading and writing teaching. To develop this study, we used documental research. The article concludes that the utilization of the mutual instruction allowed the maintenance of models of reading and writing teaching based in the systematic study of letters, of the syllables, of the sentence and, finally, of the reading of religious texts and others, which intended the constitution of religious and patriotic feelings in individuals. It also concludes that the adoption of this method, considering the working conditions of the schools, represented the lack of interest of the provincial governments in offering the minimal working conditions of the schools, mainly in reference to the guarantee of adequate education and remuneration of the teachers.
\end{abstract}

Key-words: teaching and writing history; reading teaching; writing teaching.

\title{
Introdução
}

Este texto é parte de um trabalho cuja finalidade foi investigar a história da alfabetização no Espírito Santo. Assim, tem por finalidade analisar o método de ensino da leitura e da escrita concretizado no Regimento Interno das Aulas Publicas de $1^{\text {as }}$ Letras da Província do Espírito Santo. O corpus analisado foi constituído por textos impressos ou manuscritos.. Para desenvolvimento da pesquisa, utilizamos a metodologia de pesquisa denominada documental. De acordo com Gil (2007), ela caracteriza-se pelo uso de fontes que ainda não receberam um tratamento analítico, ou que ainda podem ser reelaboradas de acordo com os objetivos da pesquisa. Nesse sentido, analisamos fontes primárias e secundárias que nos ajudaram na busca de reconstrução da história da alfabetização no Espírito Santo.

Nos tópicos que se seguem, analisaremos o Regimento Interno das Aulas Publicas de 1. ${ }^{\text {as }}$ Letras da Província do Espírito Santo e o método de ensino nele concretizado. Avaliaremos ainda que a adoção do método mútuo no Espírito Santo não foi acompanhada de medidas que contribuíram para a melhoria das condições de funcionamento das escolas públicas. 


\section{O método mútuo ou monitorial e o ensino da leitura e da escrita}

O método de ensino previsto para ser adotado nas escolas públicas do Espírito Santo no Regulamento da Instrução Pública de 1861 foi o simultâneo. Esse Regulamento, segundo nossas pesquisas, vigorou até o ano de 1873. Sobre o ensino simultâneo, Lesage (1999, p.10) explica:

É coletivo e apresentado a grupos de alunos reunidos em função da matéria a ser estudada. $\mathrm{O}$ ensino dado pelo professor não se dirige mais a um único aluno, como no modo individual, mas pode atender a cinqüenta ou sessenta alunos ao mesmo tempo.

No Espírito Santo, a indicação de adoção do método de ensino simultâneo foi feita no Regulamento de 1848, elaborado por Couto Ferraz. Mais tarde, esse método também será adotado no Município da Corte. Segundo Faria Filho (2000, p.142), ele

[...] era o que melhor atendia às especificações da instrução escolar, permitindo a organização de classes mais homogêneas, a ação do professor sobre vários alunos simultaneamente, a otimização do tempo escolar, a organização dos conteúdos em diversos níveis, dentre outros elementos.

Desse modo, o método simultâneo permitiu, no Espírito Santo, a organização das aulas de $1 .{ }^{\text {as }}$ letras em diversas classes, sob a responsabilidade de um único professor, o que propiciava ainda o funcionamento de aulas públicas a custo mais baixo. Contudo, apesar de o Regulamento de 1861 dispor sobre a adoção desse método e criar um mecanismo dificultador da adoção de outro, elementos do método mútuo foram agregados a ele com a finalidade de garantir a disciplina e a ordem nas classes.

No período de 1848 a 1882, houve, na Província, oscilações nas definições de métodos de ensino nos regulamentos. Em 1848 e 1861, havia a indicação do método simultâneo; em 1873, do Misto; em 1877, poderia ser adotado o simultâneo ou o misto. Essa oscilação indicia que, a partir da segunda metade do século XIX, na província do Espírito Santo, havia debates acerca dos métodos 
de ensino e também tentativas, por parte do Governo Provincial, de organizar e uniformizar as instituições de ensino primário, por meio da adoção de métodos, livros de leitura e definições curriculares para todas as escolas da Província.

Dos documentos que acompanhavam o Relatório apresentado à Assembleia Provincial do Espírito Santo, no dia da abertura da sessão ordinária de 1861, pelo presidente José Fernandes da Costa Pereira Junior, constava o relatório da Diretoria da Instrução Pública, de 30 de abril de 1861. O então diretor, Antonio Rodriguez de Souza Brandão, preocupado com a uniformização e a melhoria do ensino na Província, transcreveu o que foi comunicado pelo professor José Ortiz da 2. ${ }^{a}$ Cadeira da Instrucção Primaria de Victoria, a respeito do método de ensino que utilizava e dos bons resultados alcançados em sua classe.

O methodo de ensino que tem me ajudado a alcançar esses resultados, que provão uma reforma na marcha seguida até aqui em todas as escolas da província, é o eclectico, porque é uma fusão ou amalgama dos três systemas de ensino, conhecidos com a denominação de mutuo, simultâneo e individual. Creio que não é possível uma bôa eschola onde esses três systemas, dando se as mãos a propósito, não sejão recursos de incalcolavel alcance para o mestre que deseja dar e conservar sólida instrucção aos seus discípulos (DOCUMENTOS QUE ACOMPANHÃO O RELATÓRIO DO PRESIDENTE JOSÉ FERNANDES DA COSTA PEREIRA JUNIOR, 1861).

Assim, o professor, tomando como referência os resultados do seu trabalho, defendeu o uso do método eclético, que se constituía da conjugação dos três métodos até então utilizados na Província. O professor Ortiz descreveu como o método eclético era utilizado na prática na aula de leitura:

Por exemplo, para não deixar sair da memória e intelligencia infantil os nomes das lettras, as suas 25 formas tão variadas e as suas inunmeras combinações produzindo syllabas, é de mister que o menino nunca cesse de repetir o que uma vez aprendeo; para repetir com proveito seu e alheio, acatando a sentença - docendo docetur - deve tomar a outrem a lição em que quer ficar mestre. Neste exercício que multiplica o tempo do professor e fructifica ao infinito o seu trabalho, está a prova de que o uso do ensino mutuo, mas sem esquecer de velar muito para o que o alumno-mestre passe ao alumno-discípulo a instrucção tal qual recebe do professor em chefe. $\mathrm{O}$ simultaneo, individual e mutuo torna-se alternativa ou simultaneamente solidários todas as vezes que tomo a licção comumm de muitos alumnos: 
simultâneo quando explico a todos os da mesma lição de leitura por exemplo; individual e simultâneo, quando cada discípulo lê a seu turno, ao passo que os mais estão attentos seguindo com os olhos a leitura que aquele faz com a minha approvação; torna-se o ensino mútuo, quando por ocasião de algum erro comettido pelo leitor, eu, em vez de dizer lhe logo em que consiste esse erro e o modo de emendar, mando que reconsidere, e se não acha por si mesmo o acerto, passo a outro essa incumbência até que um ensina aos mais. Quando nenhum acertou, tomo a mim a questão, e então ahi apparece outra vez o ensino simultaneo (DOCUMENTOS QUE ACOMPANHÃO O RELATÓRIO DO PRESIDENTE JOSÉ FERNANDES DA COSTA PEREIRA JUNIOR, 1861).

A descrição do professor revela que o método "mixto" ou "ecléctico" era utilizado na sua sala de aula no ano de 1861. Entretanto, o Regulamento de 1861 tornou a adoção do método simultâneo "mais oficial". Nesse mesmo ano, sob a vigência desse Regulamento, foi aprovado em Resolução da Ex.ma. Vice-Presidência, de 9 de janeiro de 1871, sob proposta da Directoria da Instrução Pública, Dyonisio Álvaro Resendo, o Regimento Interno das Aulas Publicas de $1^{\text {as }}$ Letras da Província do Espírito Santo, que dispunha sobre a adoção do método mútuo.

O Regimento foi dividido em 17 Títulos: do professor; do monitor; dos chefes de classe; dos alunos; da organização das aulas; do tempo de trabalho; das distribuições dos trabalhos calligráphicos; das distribuições dos trabalhos de leitura; das distribuições dos trabalhos de grammatica; da distribuição dos trabalhos de arithimetica, da distribuição do trabalho religioso; das aulas do sexo feminino, monitora e signaes; dos castigos, das recompensas; dos exames; dos objectos das aulas; dos livros, tabellas das classes. Os títulos evidenciam a tentativa de dar uma organização às Escolas de $1 .{ }^{\text {as }}$ Letras e, também, permite visualizar que a organização nele proposta estava baseada nos métodos mútuo e simultâneo, ou no que foi denominado no Regulamento de 1873 de método misto. Também podemos dizer que a organização do ensino era instituída a partir das formas modernas de pensar a educação.

Focaremos os elementos do Regimento Interno das Aulas Públicas de $1^{\text {as }}$ Letras, que permitem entender o método preconizado para ser utilizado nas escolas e como deveria ser desenvolvido o ensino da leitura e da escrita. Assim, no primeiro título, que tratava do professor, verificamos que era seu dever: 
[...]

$\S 1 .{ }^{\circ}$ Cuidar da instrução dos seus discípulos cultivando-lhes a intelligencia, a memoria e tambem na sua educação infundindo-lhe no coração os sentimentos dos deveres para com Deos, para com a patria, paes, parentes, para com o proximo e para consigo mesmo.

$[\ldots]$

Então, o professor tinha o dever de cultivar nos seus alunos a inteligência, a memória, o respeito a Deus, à pátria, à família e a si mesmo. As aulas de $1^{\text {as }}$ letras deveriam agregar conhecimentos religiosos, lições de patriotismo e de amor à família. Conforme aponta Lesage (1999), o papel do professor nesse tipo de organização do ensino é relativamente restrito, mas não deve ser subestimado. O Regimento Interno das Aulas Públicas de $1 .{ }^{\text {as }}$ Letras definia que ele seria responsável pela realização de dezoito tarefas, entre as quais podemos citar as atividades de escrituração de livros de matrícula e de acompanhamento do nível de aprendizagem dos alunos, além do ensino aos alunos de aspectos importantes relativos à leitura e à escrita, da organização da lista dos chefes de sala. Nesse caso, podemos dizer que o professor era o centro da sala.

Os monitores e, também, os chefes das classes eram os auxiliares dos professores no cumprimento de seus deveres. Assim, para as aulas de $1^{\text {as }}$ letras, o Regimento criou uma organização hierárquica constituída por agentes da ação educativa: professor, monitores, chefe das classes e alunos. Essa organização era um dos elementos essenciais que caracterizava o método de ensino mútuo ou monitorial.

O Regimento estabelecia ainda atribuições para cada um desses agentes. O professor era a autoridade máxima. O monitor era o aluno que mais se distinguia em "intellegencia, merito e conducta". O elenco de suas obrigações indica que ele seria um coadjuvante do professor em matéria de inspeção de todas as classes, de fiscalização dos alunos e responsável por "denunciar" aqueles que cometessem transgressões ou infrações. Ele deveria ainda substituir o chefe da classe em suas faltas, lecionando nas respectivas classes, manter a disciplina ("fazer guardar silêncio e ordem, evitando a confusão ou conversação e motim nas classes" - Art. $\left.2 .^{\circ}, \S 3 .^{\circ}\right)$ e conceder aos colegas qualquer tipo de autorização para se ausentarem das classes. Segundo Lesage (1999, p.19), eles seriam "no nível das práticas [...], o elemento fundamental [...] o agente obreiro do método".

O chefe da classe era o aluno "[...] que mais se distinguia na classe, imediatamente superior áquella em que houver de ensinar" (Art. 3. ${ }^{\circ}$ do Regimento Interno das Aulas Públicas de $1 .^{\text {as }}$ Letras). A ele caberia tomar lições de leitura dos colegas, manter a ordem e o silêncio na sua classe, receber do professor os 
materiais necessários às aulas (ardósias, lápis, papel e outros objetos) e comunicar ao monitor as infrações dos alunos para ser levado ao conhecimento do professor. Caberia aos alunos, por sua vez, obedecer ao professor, aos monitores e aos chefes das classes, estudar as matérias escolares e serem avaliados pelo professor e pelos chefes de classe.

Dessa forma, o monitor tinha atribuições mais gerais e ligadas à disciplina. Eles eram os agentes que mantinham, por um lado, uma relação mais direta com o professor e, por outro, com os chefes das classes. Dessa forma, se compararmos a organização e atribuições dos agentes educativos dispostas pelo método mútuo e descritas por Lesage (1999) com a prevista no Regimento Interno das Aulas Públicas de 1. ${ }^{\text {as }}$ Letras na província do Espírito Santo, podemos concluir que são semelhantes. Segundo esse autor, “[...] o método mútuo divide a responsabilidade entre o professor e os alunos encarregados da função de monitores" (LESAGE, 1999, p.19). Os ajudantes diretos dos professores recebiam, segundo Lesage (1999), as denominações de monitores gerais e de monitores particulares, enquanto no Regimento Interno das Aulas Públicas de 1. as Letras, recebiam, respectivamente, a denominação de monitores e de chefes de classes.

Os objetos a serem utilizados nas aulas de $1 .{ }^{\text {as }}$ letras também eram previstos no Regimento, no seu Art. 90. Assim, cada aula deveria ter, entre outros objetos, uma imagem do Senhor Crucificado " [...] collocada na parede por cima da cadeira do professor, bem acondicionada em uma caixa ou santuário de madeira e decente"; "bancos e escrivaninhas inclinadas com tinteiros fixos, collocadas em frente ou ao lado do professor"; um relógio colocado em frente ao professor; um quadro de madeira pintado de preto, com esponja e giz; ardósia, papel, tinta, lápis, livros para os meninos pobres; "modelos de escriptas, ou traslados"; dois quadros, um branco com moldura dourada para lançar os nomes dos meninos ótimos e um negro para escrever os nomes dos "meninos máos". Para cada aula, deveria haver ainda o regulamento e o regimento.

Segundo Lesage (1999, p.16), o uso das ardósias constitui “[...] uma inovação essencial do método mútuo, de que outras escolas não fazem uso". Segundo o autor, elas são utilizadas em quase todas as disciplinas. Conforme escrito no Regimento Interno das Aulas Públicas de $1 .{ }^{\text {as }}$ Letras, elas deveriam ser utilizadas apenas nas aulas de caligrafia para os alunos iniciantes. Essa medida poderia ajudar na economia desse tipo de material, porém, o relatório apresentado ao presidente da Província, Domingos Monteiro Peixoto, pelo inspetor-geral da Instrução pública, Joaquim Gomes da Silva Netto, em julho de 1875, informa que não existiam em nenhuma escola da Província os materiais e utensílios imprescindíveis às Escolas de 1. as Letras previstos no Regimento e que o estado das escolas era lamentável. 
O Regimento definiu ainda sobre a organização do mobiliário nas salas de aula de 1 as $^{\text {as }}$ letras. Os bancos e as escrivaninhas deveriam ser dispostos na frente ou ao lado do professor, de modo que este, de sua cadeira, colocada em um tablado mais alto, pudesse observar o que se passava na sala, mesmo nos lugares mais distantes. Sobre a mesa do professor, deveria haver uma "campainha, um tinteiro e arieiro, lápis, canivete, regua e ardósia".

Nos lugares, cidades, vilas com maior número de crianças em idade escolar, as aulas deveriam ser divididas em seções, ocupando a mesa do professor também lugar central. O tempo de trabalho na sala de aula deveria ser, de acordo com o Regimento, de cinco horas e meia, divididas conforme horário para as aulas das turmas dos sexos feminino e masculino.

O tempo de cada matéria, em cada dia da semana, foi rigorosamente distribuído. Assim, por exemplo, na segunda-feira, das $8 \mathrm{~h} 30 \mathrm{~min}$ horas às $9 \mathrm{~h} 30 \mathrm{~min}$, nas classes dos meninos, seria trabalhada a escrita e, nas classes das meninas, a escrita e a leitura em prosa. Das $9 \mathrm{~h} 30 \mathrm{~min}$ às $10 \mathrm{~h} 30 \mathrm{~min}$, para os meninos seria trabalhada a leitura e, para as meninas, a leitura em versos. Das $10 \mathrm{~h} 30 \mathrm{~min}$ às $11 \mathrm{~h} 30 \mathrm{~min}$, os meninos e as meninas estudariam gramática. Das $11 \mathrm{~h} 30 \mathrm{~min}$ às $12 \mathrm{~h}$ seria ensinada aritmética para as meninas e leitura em versos para os meninos. Das $12 \mathrm{~h}$ às $13 \mathrm{~h} 30 \mathrm{~min}$ seria ensinada aritmética para os meninos. Exceto nas quintas-feiras em que era ensinada aritmética, no último horário, nas classes do sexo feminino, deveriam ser ensinados costura e outros trabalhos de agulha.

As aulas para as turmas do sexo feminino eram um pouco diferentes, pois, para essas turmas, devia ser escolhida uma monitora dentre as mais adiantadas e de melhor conduta. Não havia menção às chefas de classes. Entretanto, havia o detalhamento de dois tipos de sinais a serem utilizados pelas alunas para indicar pedidos de autorização para o afastamento das aulas: a elevação e apresentação do dedo índex indicavam pedido para ir beber água e a do dedo índex com o médio assinalava pedido para satisfazer qualquer outra necessidade. $\mathrm{O}$ uso dos sinais visava garantir o silêncio nas aulas.

A classificação dos alunos era feita semanalmente e atuava como mecanismo que, certamente, proporcionava a competição entre eles. Ao final do ano, deveriam também ocorrer os exames. Eles eram preparados pelo diretor-geral na capital, e pelos inspetores e delegados nos distritos, que indicavam o dia e horário dos exames. Eram convidados ainda examinadores para esse fim. Assim, conforme o Regimento, os alunos deviam ser examinados individualmente em todas as matérias. Em relação à escrita, tinham que "[...] escrever algum trecho para conhecer a ortographia e caligraphia, escrevendo a primeira linha em letra maiúscula, e os demais em cursivo" (Art. 89). Findo o exame, os examinadores definiriam pela aprovação (A) ou reprovação (R) dos alunos. O resultado do exame era registrado em ata, devidamente assinada e encaminhada ao diretor 
do ensino. Para as aulas das turmas do sexo feminino, deviam ser convidadas duas senhoras para avaliar os trabalhos de agulha.

O Regimento definiu deveres do professor referentes ao ensino da escrita e da leitura. No que dizia respeito ao aprendizado da escrita, o professor deveria:

[...]

$\S 16$. Explicar a forma das letras, as linhas de que se formão, que inclinação, largura e extensão devem ter, mostrando a postura do corpo, a maneira de pegar a penna, corrigindo-a quando defeituosa.

A interpretação do $\S 16$, do Art. $1 .^{\circ}$, evidencia que o trabalho com a escrita deveria privilegiar os aspectos formais da escrita das letras, a postura do corpo e o modo correto de segurar a pena utilizada para escrever. Os trabalhos de escrita restringiam-se à caligrafia. Esse componente de ensino nas Escolas de $1^{\text {as }}$ Letras, assim como o de leitura e de gramática, deveria seguir prescrições detalhadas previstas no Regimento. Os trabalhos caligráficos deveriam ser realizados de segunda a sexta-feira, no início das aulas. Ao chegarem à classe, os alunos deveriam tomar seus lugares, indicados de acordo com a classificação que tivessem nessa matéria. Dez minutos após o começo das aulas, atendendo a um sinal de campainha do professor, deveriam ficar de pé para fazer uma pequena oração, que era recitada pelo professor e repetida pelos alunos de uma só vez (Art. 12).

Após a oração e mediante um sinal do professor, os chefes das classes alunos mais adiantados em caligrafia - deveriam encaminhar-se à mesa do professor para receber dele papel, penas, exemplares e outros materiais necessários às aulas e distribuí-los entre os colegas. Cada aula poderia ter até oito classes.

Durante o tempo em que os alunos escreviam, o professor e o monitor deviam percorrer as classes para verificar e corrigir a má posição de seus corpos "e o modo defeituoso de pegar na penna" (Art. 16). Esse tipo de atividade deveria ser feita silenciosamente. Somente à medida que todos os alunos iam terminando, o chefe da classe tomava o seu lugar, designado pelo professor, para fazer sua prova de caligrafia.

Quando o monitor percebia que as classes estavam concluindo a prova, comunicava esse fato ao professor, que, ao sinal da campainha, anunciava o início da correção das provas caligráficas, começando das classes mais atrasadas. Diante da mesa do professor, as provas feitas pelos alunos eram entregues pelo chefe da classe por ordem de adiantamento dos alunos. O professor fazia, então, minuciosamente, a correção de uma escrita para que toda a classe aproveitasse, e apontava ligeiramente, nos outros trabalhos, os "defeitos mais salientes" (Art. 
20). Ele devia observar o tempo, para que a correção não ultrapassasse uma hora, e devia cuidar ainda, para compensar, no dia seguinte, a correção que foi abreviada em decorrência do tempo. A correção dos trabalhos de caligrafia deveria ser feita individualmente pelo professor.

As tabelas das classes previam os conteúdos de escrita a serem trabalhados em ordem de dificuldades. Em relação à escrita definiam:

$1 .^{\circ}$ Linhas rectas e curvas.

2. ${ }^{\circ}$ Outras formadas de linhas primitivas.

3. ${ }^{\circ}$ Linhas superiores e inferiores.

4. ${ }^{\circ}$ Em papel A B C em letras maiusculas.

5. ${ }^{\circ} \mathrm{A} \mathrm{B} \mathrm{C} \mathrm{em} \mathrm{letras} \mathrm{minusculas.}$

6. ${ }^{\circ}$ Sentença em cursivo de exemplares ou dictadas.

Quanto aos alunos principiantes, o Regimento, no seu Art. 13, definia que deveriam começar os exercícios caligráficos em ardósia. Dessa forma, eles começavam a fazer uso de papel somente após terem alcançado nível de desenvolvimento mais adiantado. Após a conclusão dos trabalhos caligráficos, ao sinal da campainha do professor, os alunos mudavam de lugares, segundo a sua classificação para a aula de leitura. Assim, para todas as classes, a segunda aula, que tinha início às $9 \mathrm{~h} 30 \mathrm{~min}$ era de leitura. Nessa direção, o Regimento Interno das Aulas de $1{ }^{\text {as }}$ letras definia como dever do professor:

\section{$[\ldots]$}

$\S 14$. Habituar o alumno a ler claro, distinctamente e com pauza, a pronunciar corretamente e a entender o que lê, ensinando a distinguir as differentes partes da phrase e fazer as pautas necessárias, á leitura intelligível, acostumando-o a ler com um som simples, natural e sem declamação evitando a monotonia.

$\S 15$. Fazer o aluno pronunciar com clareza e exactidão a vogal e consoante e conhecer quaes as letras que tem sons diversos.

Esses parágrafos permitem visualizar que o trabalho com a leitura compreendia a pronúncia clara e exata dos sons consonantais e vocálicos, a aprendizagem de que as letras têm vários sons, o entendimento dos textos lidos, a distinção dos elementos de uma frase, além do que poderíamos chamar de 
leitura fluente. Assim, podemos observar no Regimento a tentativa de conciliar, no ensino da leitura, elementos de decifração da escrita e de entendimento de textos, observando uma escala gradativa. Como um dos objetivos centrais das aulas de $1^{\text {as }}$ letras era o cultivo da memória, podemos inferir que o trabalho de aprendizagem da decifração da escrita era feito por meio da memorização dos sons e das letras.

As lições de leitura deviam iniciar pelas classes mais adiantadas. O professor tomava a leitura dos alunos "debaixo do maior silêncio" (Art. 25). Os alunos das classes mais adiantadas deveriam ler prosa e verso em dias alternados e letra manuscrita uma vez por semana. O professor só deveria passar para a leitura de versos após os alunos aprenderem a ler corretamente. Dessa forma, o professor só tomava a leitura nas classes mais adiantadas: primeira e segunda. Nas demais, o trabalho deveria ser feito pelo chefe da classe. Ele tomaria a lição dos codiscípulos "à meia voz" para não perturbar aos outros alunos. Ao professor caberia, nesse momento, circular pelas classes para verificar o cumprimento do dever pelos chefes das classes. Após terminar o trabalho, o chefe da classe deveria ficar de pé, diante da classe, cuidando para que fosse conservado o silêncio. Nesse contexto, é importante acentuar que o trabalho inicial de ensino da leitura ficava a cargo dos chefes de sala.

O monitor deveria comunicar o professor o término dos trabalhos de leitura. Ao sinal da campainha do professor, os chefes, começando pelas classes mais atrasadas, deviam dar "[...] parte dos alumnos que não souberão as lições, afim de serem castigados ou reprehendidos". Os castigos e as repreensões também foram previstos no Regimento:

Art. 73. - Os castigos serão proporcionados ás faltas, conforme a idade e natureza das alumnas e serão os seguintes:

$\S 1 .^{\circ}$ Reprehensão particular

$\S 2 .^{\circ}$ Reprehensão publica

$\S 3 .^{\circ}$ De pé em seu lugar.

$\S 4 .^{\circ}$ De pé em cima do banco.

$\S 5 .^{\circ}$ Ajoelhado em seu lugar.

$\S 6 .^{\circ}$ Ajoelhado no banco.

$\S 7 .^{\circ}$ Mudança do primeiro para o último lugar.

$\S 8 .^{\circ}$ Separação da classe que pertencer para outra inferior.

$\S 9 .^{\circ}$ Retenção na aula por uma hora após concluídos os trabalhos.

$\S 10$. Comunicacção ao pai ou encarregado;

$\S 11$. Nome escrito no quadro negro até que se corrija.

§ 12. Expulsão com exposição dos motivos pelo professor, informação do inspetor, delegado e aprovação do diretor geral. 
Segundo Lesage (1999), Bell e Lancaster, idealizadores do método de ensino mútuo, recorriam à emulação por não acreditarem "no simples desejo de aprender". Nesse sentido, o Regimento Interno das Aulas Públicas de 1. as Letras estabeleciam o uso de "estímulos" que poderiam levar o aluno a mudar um comportamento considerado inadequado ou a buscar melhorar seu desempenho nas matérias escolares. As aulas de $1 .^{\text {as }}$ letras deveriam ter três quadros: dois para os nomes dos alunos considerados ótimos e um para os nomes dos meninos considerados maus. Os dois primeiros deveriam ser brancos e ter moldura dourada; eram denominados quadros de honra; o terceiro era negro e de moldura negra.

Esses castigos, combinados com as avaliações semanais e com as recompensas para os alunos que sobressaíam dentre os demais, também previstas no Regimento, certamente criavam um clima constante de competição entre os alunos. O sistema também conferia poderes aos bons alunos, ou seja, para cada aluno que demonstrasse bom comportamento ou conhecimento da matéria, foram estabelecidas recompensas, tais como receber "distintivo de 1.. "; ter o nome escrito no quadro de honra, ser escolhido o chefe da sala. Desse modo, tanto as sanções como as recompensas eram hierarquizadas de acordo com o comportamento do aluno. Ao professor caberia escolher as sanções e os elogios aplicáveis.

Segundo Lesage (1999), esse sistema de sanções e penas choca-se com os conceitos atuais da educação primária e da pedagogia. Entretanto, é importante observar que os castigos físicos não aparecem na lista das sanções. Segundo ele, na escola mútua e, podemos dizer também, no Regimento Interno das Aulas Públicas de 1. as Letras, os castigos físicos foram banidos. Assim, segundo Octave Greard (apud LESAGE, 1999, p.22): “[...] não será demais reconhecer terem procurado substituir no coração dos alunos o sentimento de honra, ou, como disse M. de Laborde, o sentimento da vergonha bem administrado".

O Regimento definiu ainda os livros de leitura e de escrita que seriam usados nas escolas: Alphabeto e Syllabarios, de Luis Francisco Midosi, ou Alphabeto e Syllabarios; Methodo Facillimo, por Monteverde; $1 .^{\circ}$ livro de Leitura, um dos dois - Leitura em Versos por Antonio Marques Rodrigues, ou Selecta Brazilense, pelo major José Marcellino Pereira de Vasconcellos; Leitura em Manuscrito, por Duarte Ventura; Leitura em versos, pelo cônego Pinheiro, ou por Dr. Francisco de S. Garcia, última edição precedida de biographia do autor e de um juízo critico do cônego Pinheiro; Assunção ou Meandro Poético; Caligraphia, por Parker. A indicação dos livros de leitura observava rigorosamente as tabelas das classes referentes ao ensino da leitura: 
1. ${ }^{\circ}$ Alphabeto $-1 .^{\mathrm{a}}$ e 2. ${ }^{\mathrm{a}}$ lição de leitura do Methodo Facillimo por Monteverde ou Francisco Midosi.

2. ${ }^{\circ}$ Syllabario idem idem.

3. ${ }^{\circ}$ Prosa idem por Antonio Marques Rodrigues, ou Selecta Brazilense por P. de Vasconcellos.

4. ${ }^{\circ}$ Historia sagrada pelo cônego Pinheiro.

$5 .^{\circ}$ Verso e manuscripto pelo cônego Pinheiro e Duarte Ventura.

As tabelas de classe definiam o que seria ensinado em cada uma delas. Nesse sentido, além de padronizar o método de ensino, o Regimento Interno das Aulas Públicas de $1 .{ }^{\text {as }}$ Letras definiu os livros que deveriam ser utilizados em todas as classes. A sua escolha, como pode ser visualizado, permitiu garantir a graduação das classes de acordo com os níveis de aprendizagem.

Na descrição do professor Ortiz, em 1861, ele mencionou o uso de livros do português Emilio Achilles Monteverde em sua classe. Na 16. ${ }^{a}$ edição do Methodo Facillimo Para Aprender a Ler Tanto Letra Redonda Como a Manuscripta no Mais Curto Espaço de Tempo Possível, a partir da 5. página, Monteverde destaca os três principais métodos ou modos de ensino elementar: o ensino individual, o ensino simultâneo e o ensino mútuo. Segundo ele, o ensino individual era o mais antigo e "[...] consiste em o professor chamar os discípulos um após o outro, a cada um dos quaes toma a lição de ler, escrever, contar, etc.; de modo que nenhum aproveita das lições dadas aos seus companheiros" (MONTEVERDE, 18-, p.5).

Dessa forma, para a turma de sessenta alunos com aulas que duravam seis horas por dia, o professor poderia dedicar-se durante seis minutos, a cada aluno. No restante do tempo, os alunos ficavam entregues a si próprios, o que gerava indisciplina. Segundo o autor, esse método era considerado defeituoso e, apesar de ter sido adotado em diversos países, sabe-se que era raramente bem sucedido.

Por sua vez, segundo Monteverde (18-, p.5), o método simultâneo consistia "[...] em dividir as classes ou turmas, segundo ás suas forças, e fazer seguir ao mesmo tempo a toda uma classe a mesma lição de leitura, escripta, calculo, etc., isto é, o Professor a cada um em voz alta, e os outros o vão seguindo em seus livros ou cadernos". Nesse sentido, os alunos valiam-se dos ensinamentos e das leituras feitas pelo professor.

Esse autor considera que o método mútuo era o simultâneo modificado. Para ele, “[...] as creanças, grande imitadoras, imitão mais facilmente os seus companheiros do que as pessoas de mais idade, e é sobre esse principio que se fundou o ensino de umas creanças ás outras" (MONTEVERDE, 18-, p.6). Acena que, numa escola, com número grande de alunos só seria necessário um professor, pois os monitores ou decuriões atuariam como mestres e transmitiriam 
aos colegas o ensino que receberam em uma classe superior. Nesse sentido, Monteverde considera que esse método era superior aos dois primeiros, mas aplicável apenas em estudos elementares, como a leitura e a escrita.

Além de mencionar os métodos ou modos de ensino da escola elementar, Monteverde aponta a existência de três métodos para ensinar a ler e a escrever: o antigo, o de soletração e o sem soletração. O método antigo

consiste em conservar ás letras os seus nomes usuaes de: a, bê, cê, dê, é, éfe, gê, agá, i, jota, éle, éne, éme, ó, pê, quê, érre [...] e nomeal as todas successivamente antes de pronunciar a syllaba, a qual por conseguinte, n'este caso, tem tantos elementos quantas são as letras de que ellas se compõe (MONTEVERDE, 18-, p.7).

O novo método de soletração, segundo o autor da cartilha, diferia do primeiro, porque as consoantes são pronunciadas "como se fossem seguidas de e mudo: B be, $\mathrm{C}$ ce ou ke, D de...". Dessa forma, o método consistia em dar às letras um nome semelhante ao que elas tinham na leitura e em considerar as sílabas como verdadeiros elementos da palavra. Sendo assim, a leitura devia ser feita por sílabas e não pela decomposição das letras, como no método antigo.

Monteverde considera que os dois métodos tinham vantagens e desvantagens, apontadas pelos seus defensores. Contudo, para ele, o melhor método era aquele que ensinava com maior rapidez e formava melhores discípulos. No seu livro, podemos verificar a presença de textos religiosos, como orações, textos informativos tratando sobre as invenções e as descobertas portuguesas, entre elas, a do Brasil, em 1500, por Pedro Álvares Cabral, e sobre a história de Portugal.

Segundo Villela (1999, p.148), ao analisar se a Escola Normal de Niterói teve alguma influência no desdobramento do método mútuo em práticas concretas, na província do Rio de Janeiro e em outras, ele "[...] associava a leitura e a escrita (o que antes acontecia separadamente); utilizava materiais didáticos novos, como tabuinhas de areia, lousas, quadros de parede, etc.; abolia quase por completo o uso de livros e atendia muitos alunos simultaneamente". Manacorda (1995) também compartilha da opinião de Villela (1999) quanto à associação entre leitura e escrita. Porém, o método concretizado no Regimento Interno das Aulas Públicas de $1^{\text {as }}$ Letras previa a utilização de livros para as aulas de leitura, escrita e gramática e mantinha a dissociação entre leitura e escrita. Isso pode ser evidenciado por meio das tabelas de classe referentes a cada uma das matérias e, também, pela existência de livros e tempos distintos para o trabalho com as duas matérias. 
O método mútuo adotado na década de 1870, na província do Espírito Santo, manteve, também, nas tabelas de classe, procedimentos didáticos que começavam pelo treino das mãos, ao ensino das letras, das sílabas, das palavras, frases e textos. Nesse sentido, o método de ensino da leitura e da escrita concretizado e indicado nos livros era de marcha sintética.

\section{Considerações finais}

Segundo Lins (1999), em 1816, o Correio Braziliense, em Londres, trazia artigos escritos por Hipólito da Costa Furtado de Mendonça sobre o método de Joseph Lancaster. Nessa série de artigos, de acordo com Lins (1999), o autor aconselhava Portugal e o Brasil a adotarem o método seguindo o exemplo de países como Canadá, Estados Unidos, Escócia, Irlanda e França. Bastos (1999) também menciona a série de artigos de Hipólito e evidencia que a introdução do método no Brasil, no ano de 1827, foi anterior à sua oficialização.

Lins (1999) aponta que a defesa do método feita por Hipólito se baseava principalmente na necessidade de educar a todos. Entretanto, nem todos precisavam dos mesmos conhecimentos, pois nem todos iriam ocupar posições privilegiadas na sociedade. Nesse sentido, segundo a autora, a defesa do método é

[...] compatível com o discurso de Adam Smith (1723-1790) em sua obra A riqueza das nações. O princípio é não ocupar uma classe destinada aos ofícios manuais e mecânicos com o estudo das ciências abstratas. Somente a educação elementar ou primária seria compatível com todas as atividades desta classe, uma que serve, sobretudo, para cultivar o espírito, manter os indivíduos em harmonia com o Estado (LINS, 1999, p.77).

Assim, se considerarmos as matérias escolares propostas no Regimento Interno das Escolas de $1 .{ }^{\text {as }}$ Letras, leitura, escrita, rudimentos de gramática e aritmética, catecismo, história sagrada e da Igreja, nós podemos concluir que a educação no Espírito Santo seguia essa mesma tendência de ofertar à população uma educação compatível com o lugar que a maioria deveria ocupar na sociedade. Nesse sentido, é interessante apontar também que essa sua adoção possibilitava expandir a educação sem a necessidade de aumentar os gastos, pois um mesmo professor, com o auxílio dos monitores e chefes de classe, poderia ensinar uma grande quantidade de crianças ao mesmo tempo. Assim, a 
sua principal vantagem era de caráter econômico.

Bastos $(1999$, p.116) assinala que a adoção do método mútuo representou um "[...] processo de incorporação das modernidades dos países centrais, em fase de industrialização e conseqüente formação de cidadãos adaptados a essa realidade". Ele nasceu com o processo de industrialização. Entretanto, segundo ela, com base em Xavier (1994), no Brasil, a sua adoção representou exatamente a falta de interesse do Estado agroexportador e escravocrata de oferecer condições mínimas de funcionamento das escolas, principalmente quanto à garantia de formação e remuneração adequada dos professores.

Em relação ao ensino da leitura e da escrita, podemos dizer que a utilização do método mútuo possibilitou a permanência de modelos tradicionais baseados no estudo sistemático e em ordem crescente de dificuldades das letras, das sílabas, da frase e, finalmente, da leitura de textos religiosos e de outros, que visavam à constituição nos indivíduos de sentimentos religiosos e de patriotismo.

É importante enfatizar que o método proposto no Regimento exigia a utilização de materiais que propiciariam o desenvolvimento das aulas e a existência de salas amplas para abrigar as classes, que poderiam chegar a oito. Entretanto, no Espírito Santo, durante o final do Império, as medidas legais não contribuíram para melhorar as condições de funcionamento das escolas. Apesar de as leis preverem a construção de prédios escolares, as escolas continuaram a funcionar em casas alugadas, pagas pelo professor, com auxílio dos cofres públicos. Somente em 1908, com a criação dos grupos escolares, começou um movimento, ainda lento, no sentido de construir instalações apropriadas.

O Art. 49 do Regulamento de 1873 previa que as escolas funcionassem em edifícios próprios especialmente construídos para essa finalidade. Entretanto, previa ainda que, na ausência de prédios escolares, poderiam ser alugadas, provisoriamente, casas que tivessem condições e acomodações suficientes para abrigar o professor. Além disso, os professores casados, na falta de escolas para o sexo feminino, poderiam receber em suas casas meninas pobres para educar, mediante autorização do inspetor-geral e subvenção de dois mil réis para cada aluna. Nessas escolas, as esposas dos professores eram incumbidas pelo Regulamento de oferecer ensino de costura e outros trabalhos de agulha para as alunas. No Regulamento de 1877, também foi definido que as escolas funcionassem em edifício próprio, porém, como o Regulamento de 1873, admitia na falta de edifícios, o aluguel de casas com as devidas acomodações.

Em relação ao restante do material escolar, o Regulamento de 1873 mencionava que cada escola deveria ter livros de matrícula dos alunos, de atas de exames e de registro de correspondência oficial do professor. A escrituração nesses livros devia ser feita conforme orientações do inspetor-geral. No Regulamento de 1861, não havia menção a esses tipos de livros. O primeiro passo 
no sentido de constituição de materiais escolares visava garantir a escrituração de dados referentes à estatística escolar. Ainda no Art. 59 do Regulamento de 1873, ficou definido "[...] o material para o expediente das escolas, bem como os moveis que lhes forem necessários serão fornecidos pelo Inspetor Geral, á custa dos Cofres Provinciais". Os delegados literários deveriam, em suas visitas às escolas, inventariar as mobílias e os utensílios. No Regulamento de 1877 , foi definido que esse inventário deveria ser feito toda vez que ocorresse mudança de professor. Esse Regulamento determinou que houvesse nas escolas, para escrituração de informações, livros de matrícula, de atas de exames e visitas, de registro de correspondência e do inventário de material da escola.

No relatório de Marcelino de Assis Tostes, apresentado à Assembleia Legislativa da Província do Espírito Santo, em 8 de março de 1881, houve referências a mobílias e utensílios para escolas. Segundo o Presidente, quase todas as escolas estavam desprovidas de mobílias e a maior parte delas funcionava em casas alugadas. Essa situação devia-se, em parte, ao fato de o Regulamento de 1877 não prever, como o Regulamento de 1873, a responsabilidade de aquisição de móveis e outros utensílios escolares por parte do Poder Público.

Dessa forma, a escola primária na Província funcionou precariamente em casas com poucos materiais. Segundo artigo publicado no jornal Espirito-Santense sob a gerência de Manoel Antonio d' Albuquerque Rosa, em 1. ${ }^{\circ}$ de novembro de 1870 , a educação, na província não tinha sido tratada com o zelo necessário e apregoado por aqueles que governaram a Província. Alguns presidentes limitavam-se, de acordo com o artigo, a proclamar a precariedade da educação, mas sem propor medidas para a sua melhoria. Enquanto isso,

[...] o povo continua a viver enlodado na ignorância, e as pobres creancinhas crescendo sem a menor parcella da alimentação do espirito ou entregue aos cuidados de muitos daqueles que premiado com um titulo de professor de 2. ${ }^{\text {a }}$ classe ou também de $1 .^{\text {a }}$, vão nesses pobres arrayes desfructar os magros vencimentos ensinando muitas vezes o que mais ignorão (A INSTRUÇÃO..., 1870, p.1).

Desse modo, as condições para o desenvolvimento da alfabetização no Espírito Santo foram precárias durante toda a década de 1870 e décadas subsequentes. A própria adoção do método mútuo, na segunda metade da década de 1880, após os resultados insatisfatórios obtidos em outras províncias que o adotaram, evidencia a falta de interesse do governo provincial em possibilitar condições para a aprendizagem da leitura e da escrita pelas classes desprivilegiadas. 


\section{REFERÊNCIAS}

BASTOS, Maria Helena Câmara. O ensino mútuo no Brasil (1808 -1827). In: BASTOS, Maria Helena Câmara; FILHO, Luciano Mendes de Faria (Orgs.). A escola elementar no século XIX: o método monitorial/mútuo. Passo Fundo: Ediupf, 1999. p.95-118.

DOCUMENTOS QUE ACOMPANHÃO O RELATÓRIO DO PRESIDENTE JOSÉ FERNANDES DA COSTA PEREIRA JUNIOR. In: ESPÍRITO SANTO. Relatório do Presidente José Fernandes da Costa Pereira Júnior. 1861.

FARIA FILHO, Luciano Mendes de. Dos pardieiros aos palácios: cultura escolar e urbana em Belo Horizonte na Primeira República. Passo Fundo: UPF, 2000.

GIL, Antônio Carlos. Métodos e técnicas de pesquisa social. São Paulo: Atlas, 2007.

A INSTRUÇÃO PRIMÁRIA. Jornal O Espirito-Santense. Vitória: n. 13, ano 1, p. $1,1870$.

LESAGE, Pierre. A pedagogia nas escolas mútuas do século XIX. In: BASTOS, Maria Helena Câmara; FILHO, Luciano Mendes de Faria (Orgs.). A escola elementar no século XIX: o método monitorial/mútuo. Passo Fundo: Ediupf, 1999. p.9-24.

LINS, Ana Maria Moura. O método Lancaster: educação elementar ou adestramento: Uma proposta para Portugal e Brasil no século XIX. In: BASTOS, Maria Helena Câmara; FILHO, Luciano Mendes de Faria (Orgs.). A escola elementar no século XIX: o método monitorial/mútuo. Passo Fundo: Ediupf, 1999. p. 73-94.

MANACORDA, Mario Alighiero. História da educação: da antiguidade aos nosso dias. 4.ed. São Paulo: Cortez, 1995.

MONTEVERDE, Emilio Achilles. Methodo facillimo para aprender a ler tanto letra redonda como a manuscripta no mais curto espaço de tempo possível. 16.ed. 18-. Disponível em: <http://www.redalfa.estudiantesunlu.com.ar/galerias/portugal/ galmethodofacillimo1899/index.php?list=1\&page=1>. Acesso em: 18 dez. 2007.

VILLELA, Heloisa. O ensino mútuo na origem da primeira escola normal do Brasil. In: BASTOS, Maria Helena Câmara; FILHO, Luciano Mendes de Faria (Orgs.). $A$ escola elementar no século XIX: o método monitorial/mútuo. Passo Fundo: Ediupf, 1999. p. 9-24.

Texto recebido em 10 de abril de 2010 .

Texto aprovado em 23 de dezembro de 2010. 